\title{
Research and Practice on the Cultivating College Students' Innovation and Entrepreneurship Ability
}

\author{
Guo Jiyuan \\ College of computer science \\ Xi'an polytechnic university \\ Xi'an, Shaanxi Province, China \\ e-mail: Guojiyuan2004@126.com
}

\author{
Zhang Yan \\ Department of mathematics \\ Shaanxi Xueqian Normal University \\ Xi'an, Shaanxi Province, China \\ e-mail:Yanzi0228@126.com
}

\begin{abstract}
How to develop college students' Innovative and Entrepreneurial Ability has become the urgent task of universities. We analyzed the current cultivating college students' model from the perspective of innovation and entrepreneurship ability training. On the basis of summing up its advantages and disadvantages, we put forward the cultivating model of professional talents with innovation and entrepreneurship concept. It includes three components and four basic principles. This model provides some references for other major constructing innovative talents cultivating model.
\end{abstract}

Keywords-Innovation and Enterprise; Ability; Cultivating Model; Professional Teaching

\section{INTRODUCTION}

THE ability of Innovation and entrepreneurship（IE） has gradually become an important factor to measure a country's sustainable development. Cultivating college students' ability of IE has a very important role in improving the ability of national IE. Our country attaches great importance to this. How to develop the ability of IE of college students has become an important and urgent task for all colleges and Universities.

The general office of the State Council issued "opinions about deepening the educational reform of Colleges and universities' IE in 2015. The paper points out that the IE education reform in Colleges and universities is the national implementation of innovation driven development strategy. It is an urgent to improve the quality and efficiency of the economy. It is to promote the comprehensive reform of higher education, an important measure to promote higher quality of entrepreneurship and employment of college graduates. This paper recognizes that IE education of university should combine major and enhance practice.

The material shows that combination of the IE and cultivating professional students is very important. How to do about university in cultivating students' ability of IE at present? What are the problems in this side? With this problem, we carry out depth research on existing students' cultivating model.

\section{REFLECTION ON THE MODEL OF CULTIVATING PROFESSIONAL STUDENTS}

The first student of Digital media technology had enrolled in September 2013. At present, the scale of enrollment has been maintained in a class about 30 peoples. Cultivating model of this major has been operated for three years. All teacher including the science leading teachers do a lot of hard work during this period, draw some professional teaching experience, but also found some of the problems.

\section{A. The Advantage of Professional Cultivating Model at} Present

First, IE projects and professional skills competition are important channels to promote the students' innovative ability. Since the 2013, professional teachers of digital media technology have actively guided students to participate IE projects. The students of participating in the project students 
have been up to 50. These projects including national and provincial innovation project are about 10 projects. The category of these projects covers UI design of characteristic mobile applications, entrepreneurial film design, mobile platform design, and software developing and so on. These projects provide a lot of practicing opportunities for student, improved the students' practice ability and level and enhanced students' IE ability.

Second, regular and irregular exhibition of students' creative works is conducive to enhance students' self-confidences of IE. Nearly three years, professional teachers have organized the students' works exhibition in several times. In June 2015, we carry out first time the plane works exhibition--"Shaanxi cultural graphic works exhibition". In July of the same year, we carry out "theme photography exhibition" of digital media technology department. These actively carry out exhibition activity has been recognized and praise from the leaders of college and the school, encourage creative passion of high student, construct the exemplary role for the professional learning of low grade students, promote the powerful development of digital media technology.

Thirdly, the implementation of the tutorial system that professional teachers are senior students' tutors is an important guarantee for the improvement of students' ability to innovate and Entrepreneurship. Since 2013, we have arranged the class teachers who are mostly professional teachers. Their main work of class teacher is to solve the problem that are not understanding the major of just entering college students and not adapting to the life of college or university. We arranged tutors by professional teachers for each student from the beginning of the fourth semester. The main work of tutor include cultivating students' project of IE, guiding and supervising the process of the carrying out IE project of students, guiding the development of students in the professional direction. This work is very popular with students, and generating a good effect for cultivating the ability of IE, many IE projects are generated by tutorial system.

\section{B. The Disadvantage of Professional Cultivating Model at Present}

From 2013 to 2017, school have carried out many times kinds of investigations of cultivating students model of this major, including teaching examination, student discussion of Students who are different grades, discussion of professional teachers, and Investigation based on questionnaire and so on. We found the original cultivating model of students has the following problems. First is cultivation of students' practical ability is not prominent. The time of theory teaching in some professional Curriculum is more than the time of practicing teaching. Especially, comprehensive practical links are very lack. Teaching content is relatively old. Therefore, the students have to enter into the social training institutions to be trained again before and after graduation.

Second is the lack of cultivation of students' innovative quality. The content of the experiment course is confirmatory, lack of design of innovative experiments. These problems lead students to lack opportunities of training innovative quality. The third is teaching content of some courses is single of type, lack of expansive knowledge. If the knowledge acquired by students is directly used for employment or entrepreneurship, there will be some difficulties. These problems make professional teaching of majors facing great challenges. The realistic problem is that the current curriculum plan, practice teaching and many other teaching links have not been required to join the theory and practice teaching content of innovation and Entrepreneurship.

We may safely draw a conclusion that the current cultivating model has many advantages, but there are also some shortcomings. Therefore, it is necessary to build a cultivating student model with concept of innovation and entrepreneurship for the major of digital media technology. In order to cultivate students' IE ability, combined with the characteristics of the major of digital media technology, we have integrated the training of innovative and entrepreneurial quality into the cultivation of professional ability. This method can solve a series of problems. For example, students are lack of IE ability and lack of practical ability, the design of teaching content are lack of innovation. We can form a cultivating student model with IE concept. 


\section{THE CONSTRUCTION OF PROFESSIONAL}

\section{CULTIVATING STUDENT MODEL WITH IE CONCEPT}

From September 2016, Professional teachers have carried out investigation and research in many related universities, done enough discussion. We have held many meetings on the revision and demonstration of the new professional cultivating program. Finally, we had completed the new teaching program revised in October 2017. The concept of IE had been integrated into new professional cultivating program. We established a cultivating student model with the IE concept, as shown in Figure 1.

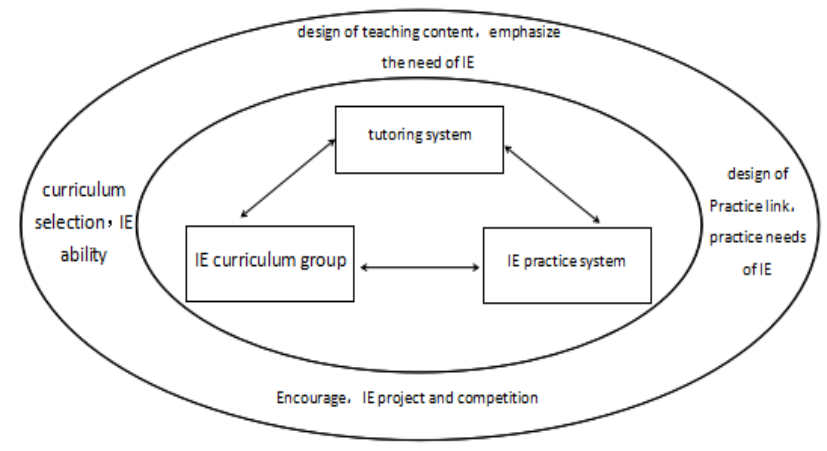

Figure 1. Cultivating students model with IE concept

The cultivating student model with IE concept of digital media technology major can be summarized as "three components and four basic points". "Four basic points" is the four basic principles that should be followed in the operation of cultivating student model with IE concept.

\section{A. Construction Principle of Cultivating Student Model} with IE Concept

All of cultivating student model construction must have its basic principle. It is the foundation to build the model. These principles of cultivating student model with IE concept of digital media technology includes the following four aspects

First, professional curriculum selection should cling to demand of IE ability. We had chosen some curriculum with new technologies or methods As many as possible to adapt to social development. We had chosen some curriculum of Enhancing students' ability of IE and practice As many as possible. In this course adjustment, we have increased many Courses with high social needs in digital media domain, such as virtual reality, augmented reality technology, OpenGL programming, python programming, machine learning, data mining and so on.

Second, the design of Practice link should close to practice needs of IE. At present, the cultivating objectives of this major include two aspects. they include the development and manufacture of game products, the design and development of network and mobile multimedia products. We have arranged the curriculum design and the professional comprehensive practice link to improve student' applying Ability for the important professional curriculum. The design of these practical links is advantageous to enhance the students' practical ability in two directions. These links include course design of data structure, course design of mobile multimedia user interface design, Practice of game product development project, course design of film editing, course design of web site design and development, Professional practice, graduated practice etc.

Third, the design of teaching content should emphasize the need of IE. At present, the teaching program of this major has been completed. Next, we're going to start writing the syllabus for every course. We put forward some principles for writing syllabus of course. In the selection of curriculum content, each course should choose the latest content in this field as far as possible. In the arrangement of the course content, each professional course should set aside some time of innovative design in class as far as possible. For example, in the middle or the end of the course, we should set aside part of the teaching time to carry out the comprehensive training basis of all knowledge has been learned in this course, in order to improve the students' ability to use the comprehensive knowledge of the curriculum.

Fourth is encouraging students to apply IE project and participate kinds of IE competition for university students. We encourage students to carry out various forms IE exercise under the guidance of instructors. From the overall situation of digital media technology students in previous years, there are about 10 applying projects each year. There are about 5 projects have 
been approved each year., there are about 15 students participate in various competitions of media design each year. A lot of students have gotten important national awards. At present, we formed the situation that enhancing IE ability of students should be through IE projects and skills competition.

\section{B. Basic Components of Cultivating Student Model with IE Concept}

We believe that cultivating student model of digital media technology with IE concept includes three core components. They are curriculum group with IE concept, the practical teaching system with IE concept, and the tutoring system of each senior student with a tutor.

First is construction of curriculum group with IE concept. Based on integrating IE concept into cultivating model, according to the latest cultivating direction of the major, we put forward the construction planning of professional curriculum group. First curriculum group of this major is game product development and manufacture of courses group. It includes Computer game programming, OpenGL programming, virtual reality, augmented reality technology, and so on. Second curriculum group of this major is design and development of network and mobile multimedia products courses group. It includes Multimedia information processing, website design and manufacture, interface design of mobile multimedia application and so on.

Second is the construction of practical teaching system with IE concept. It includes two parts: The first is set up IE experiment link in the main courses of the major. Then, we set up IE practice in different professional direction based on Different professional courses. Again, we set up IE comprehensive practice for senior students.

Thirdly, we improve the students' IE ability through regular professional skills competition and organizing students to participate in college students' IE projects. We continue to carry out various forms of IE training through the tutorial system to maintain the advantage of professional field in the past.

The last, In addition to build different levels of the practice link. We will use these measures to carry out practice teaching work. First is Close cooperation with enterprises to build a "training enterprise pool". It means selecting some better cooperative enterprises for every professional direct. We can choose the best one for this practice link before the start. Second is employing outstanding technical teacher of enterprises as part of elective courses' teacher. Third is construction of "credit replacement system". Sometimes, due to business practice, the students could fail to complete the course credits. We should allow students to apply for certificates in enterprises, and then apply to his schools. Schools should give students corresponding practice credits.

\section{CONCLUSION}

In a word, We believe that the discussion of cultivating students' IE ability is not scientific without professional cultivating. Cultivation of IE ability must root in the professional ability training. It will be rooting, flowering and bear fruit. Deeply integrating IE concept into multiple links of professional training is the foundation of promoting IE ability. These links include the orientation of cultivating, the composition of professional ability, the construction of curriculum group, the selection of specialized courses, the construction of curriculum content and the construction of practical teaching system, etc. In addition, auxiliary mechanism of various forms is an important guarantee to enhance IE ability of students. These mechanisms include encouraging college students to apply IE projects, participating in professional skills competition, organizing students to exhibition of student work, carrying out the tutorial system, etc.

\section{ACKNOWLEDGMENT}

The work described in this paper was fully supported by grant from the teaching reform Program of xi'an polytechnic university (No.2016JG59), and Educational Science Planning Project of Shaanxi province (NO.SGH17H319).

\section{REFERENCES}

[1] L.Han,"The Current Situation and Cultivating Path of College Students Innovative Ability, "Chinese University Technology Transfer, vol. Z1, pp. 121-123, 2001

[2] Y.P.Yan, "Study on the Training Mode about Innovation Ability of Business College Students based on vptp, "E-education Research, vol. 35, pp. 48-52,Oct. 2014. 
[3] J.Zuo, "Practice and Exploration of Cultivating Innovative and Entrepreneurial Ability of Engineering Students in Local Universities," CHINA UNIVERSITY TEACHING, pp.81-83, September 2010

[4] K.li, "International Comparison and reference of innovation and Entrepreneurship Education, "Studies in Dialectics of Nature, vol. 33, pp. 73-78, September 2017.

[5] W.D.Liu, Y.Lei, "Constructing Research of Curriculum System about Innovation and Entrepreneurship Based on Whole Process of Cultivating Student," Journal of National Academy of Education Administration, pp. 8-14, August 2017.
[6] X.H.Cui, "Research on the construction path of innovation and entrepreneurship guidance mechanism in Colleges and Universities," Heilongjiang Researches on Higher Education,pp. 108-110, May 2017.

[7] X.X.Yu, Y.H.Liu, "Exploration and practice of innovation and entrepreneurship education model in research universities based on three helix, " Tsinghua Journal of Education, vol. 37, pp. 111-115, April 2016.

[8] W.P.Xu, "Research on innovation and entrepreneurship education in Chinese universities from the perspective of Inclusive Education, "Heilongjiang Researches on Higher Education, pp. 67-70, September 2016. 